\title{
Body weight/ Image perception and prevalence of Obesity among 2nd year MBBS students- D.Y.Patil Medical College, Kolhapur
}

\author{
Snehdeep Patil ${ }^{1}$, Digvijay Chavan ${ }^{2}$, Anjali Ashokkumar ${ }^{2}$, Barinder Kaur ${ }^{2}$, \\ Shweta Singh ${ }^{2}$ \\ ${ }^{1}$ Assistant Professor, DY Patil Medical College, DY Patil University, Kolhapur \\ ${ }^{2}$ Student, III/I MBBS, DY Patil Medical College, DY Patil University, Kolhapur
}

\begin{abstract}
Introduction -Body image is an important element of the intricate mechanism of one's own identity. College students becoming over conscious of their body image and exhibiting strange eating behaviors is no longer a myth but a harsh reality. False preoccupation about the body has become a major concern since it has led to several unhealthy dietary practices. Objectives: (1) To assess the body weight \& image perception of 2nd MBBS students in D.Y.PATIL medical college, Kolhapur. (2) To assess prevalence of obesity among them. Material and Method: Present cross sectional study was carried out in a month of September 2013. Study was conducted among $2^{\text {nd }}$ year MBBS students of D.Y. Patil Medical College, Kolhapur India. All 150 students enrolled in $2^{\text {nd }}$ MBBS were enrolled in this study. Complete study was conducted in a day. Data was collected using pre-tested semi structured questionnaire which was self-administered. Results: Out of 150 students, 118(78.7\%) knew their body weight and remaining 32(21.3\%) students were unknown about their body weight. Our study revealed that out of 150 students, 85 students (56.7\%) were normal according to their calculated BMI, 56 students (37.3\%) were overweight and 9 students (6\%) were underweight. The prevalence of overweight/obese and underweight is high among those who did not know their body weight compared to those who knew their body weight. The prevalence of overweight/obesity was high among those who underestimated their body weight (42.3\%). Significant relationship was seen between image perception and BMI. Those participants who want to lose their weight had significantly more BMI. Conclusion and Recommendation: The study indicates that large proportion of the subjects could not appropriately classify their weight status. Overweight subjects should be better informed and empowered to follow recommended weight loss strategies.
\end{abstract}

Keywords: BMI, Body image, MBBS students, obesity.

\section{Introduction}

Globally, non-communicable diseases are increasingly recognized as a major cause of morbidity and mortality. The countries of the South-East Asia region are facing a double burden, with a heavy load of infectious diseases and an increasing burden due to non-communicable diseases. ${ }^{1}$ The increasing burden of noncommunicable diseases, particularly in developing countries including India, threatens to overwhelm already stretched health services. Several diseases come under the umbrella of non-communicable diseases and more common cause is obesity.,3

Obesity is perhaps the most prevalent form of malnutrition in developed countries. There is an increased awareness of the problem in recent years. It has been estimated to affect $20-40 \%$ of the adults and 10 $20 \%$ of the children and adolescents in developed countries. Physical inactivity may cause obesity, which in turn restricts activity. This is a vicious circle. It is the reduced energy output that is probably more important in the etiology of obesity. ${ }^{4}$ Bhuwan et al. ${ }^{5}$ in their study mentioned negative association of BMI and Self esteem. High levels of obesity dents the self esteem of an individual, as shown by the findings of study in which majority ( $82 \%$ ) of the subjects with low s elf esteem scores were found to be obese while most ( $71.43 \% \%$ ) subjects who were having high self esteem scores have BMI levels less than $25 \mathrm{Kg} / \mathrm{m}^{2}$. Hemant et al. in their study also have mentioned the significant association of high BMI with Hypertension and Diabetes Mellitus. ${ }^{6,7}$

Body image is an important element of the intricate mechanism of one's own identity. Gardner ${ }^{8}$ defines it as "the mental picture we have of our body's measures, contours and shape; and our feelings related to these characteristics and to our body parts". The subjective component of body image refers to one's satisfaction with their own body size or specific body parts. The socio-cultural environment seems to be an important variable in the development of distortions and subjective body image disorders. ${ }^{9}$

College students becoming over conscious of their body image and exhibiting strange eating behaviors is no longer a myth but a harsh reality. False preoccupation about the body has become a major concern since it has led to several unhealthy dietary practices. It has been reported that girls feeling overweight were more likely to engage in unhealthy weight control practices than those who reported feeling that they were of normal weight or underweight. Longitudinal studies have indicated that dieting also predicts weight gain and 
obesity. ${ }^{10,11}$ Weight perception is one of the motivating factors for weight control behaviors ${ }^{12}$ and is a better predictor than actual weight for students to diet or exercise. ${ }^{13}$

For preventing and reducing excess weight, the efficiency and efficacy of strategies to be designed and applied in the clinical practice and for disseminating information to the general population rely on one's realistic perception and self-awareness of their own body based on a real body size. This can be a valuable instrument in outpatient settings as an additional tool for clinically evaluating those seeking professional help due to body weight concerns.

The failure to accurately recognize their own overweight status prior to becoming obese may prevent them from changing behaviors that might contribute to additional weight gain. Therefore, it is important to understand the magnitude of weight status distortions within persons with BMI scores within the overweight range. ${ }^{14}$

\section{Materials And Methods}

Present cross sectional study was carried out in a month of September 2013. Study was conducted among $2^{\text {nd }}$ MBBS students of D.Y. Patil Medical College, Kolhapr India. All 150 students enrolled in $2^{\text {nd }}$ MBBS were enrolled in this study. Complete study was conducted in a day. Data was collected using pre-tested semi structured questionnaire which was self-administered. Initially all study participants were informed about the study and their consent was taken. Then each question was explained while the students fill them with clarifications of doubts. Students were asked whether they knew their body weight, how they perceive themselves (normal/underweight/overweight), and their desired weight. After filling of questionnaire, each student was subjected to Body Mass Index measurement. Height was measured with the help of stadiometer and weight was observed by standard weighing machine.

BMI was calculated from following formula ${ }^{4}$

Body mass Index $=\frac{\operatorname{Mass}(\mathrm{kg})}{[\operatorname{Height}(\mathbf{m})]^{2}}$

Classification of adults according to $\mathrm{BMI}^{4}$

\begin{tabular}{|l|l|}
\hline CLASSIFICATION & BMI \\
\hline Underweight & $<18.50$ \\
\hline Normal Range & $18.50-24.99$ \\
\hline Overweight & $\geq 25.00$ \\
\hline
\end{tabular}

III. Results

Table 1: Distribution of study subjects according to sex and age

\begin{tabular}{|c|c|c|}
\hline & & Frequency $(\%)$ \\
\hline \multirow{2}{*}{ Sex } & Male & $92(61.3)$ \\
\hline & Female & $58(38.7)$ \\
\hline \multirow{8}{*}{ Age } & 18 & $1(0.7)$ \\
\hline & 19 & 37 (24.7) \\
\hline & 20 & $51(34.0)$ \\
\hline & 21 & $41(27.3)$ \\
\hline & 22 & $11(7.3)$ \\
\hline & 23 & $8(5.3)$ \\
\hline & 24 & $0(0)$ \\
\hline & 25 & $1(0.7)$ \\
\hline \multicolumn{2}{|c|}{ Total } & $150(100)$ \\
\hline
\end{tabular}

In our study out of total 150 study subjects $92(61.3 \%)$ were male students and $58(38.7 \%)$ were female students. Maximum number of students was in age group of 20 years i.e. 51 (34\%) students followed by $41(27.3 \%)$ students in age group of 21 years. Few students (13.33\%) were above 21 years of age.

Table 2: Distribution according to weight awareness and BMI (n-150)

\begin{tabular}{|c|c|c|}
\hline & & Frequency (\%) \\
\hline \multirow{2}{*}{ Knowing Their Weight } & Yes & $118(78.7)$ \\
\hline & No & $32(21.3)$ \\
\hline \multirow{3}{*}{$\begin{array}{l}\text { Distribution according to } \\
\text { BMI }\end{array}$} & Normal & $85(56.7)$ \\
\hline & Overweight & $56(37.3)$ \\
\hline & Underweight & $9(6.0)$ \\
\hline \multicolumn{2}{|l|}{ Total } & $150(100)$ \\
\hline
\end{tabular}


Among 150 study subjects, $118(78.7 \%)$ knew their body weight and remaining $32(21.3 \%)$ students were unknown about their body weight. Our study revealed that out of 150 students, 85 students $(56.7 \%)$ were normal according to their calculated BMI, 56 students $(37.3 \%)$ were overweight and 9 students $(6 \%)$ were underweight.

Table 3: Distribution according to weight estimation and image perception

\begin{tabular}{|c|c|c|}
\hline & & Frequency $(\%)$ \\
\hline \multirow{3}{*}{ Weight Estimation (n-118) } & Correct & $27(22.9)$ \\
\hline & Overestimation & $13(11)$ \\
\hline & Underestimation & $78(66.1)$ \\
\hline \multirow{3}{*}{ Image Perception (n-150) } & Normal & $84(56)$ \\
\hline & Overweight & $44(29.3)$ \\
\hline & Underweight & $22(14.7)$ \\
\hline \multirow{3}{*}{ Desired Body Weight (n-150) } & To add Weight & $36(24)$ \\
\hline & To lose Weight & $60(40)$ \\
\hline & To be with present Weight & $54(36)$ \\
\hline
\end{tabular}

Out of 118 students who knew their body weight, 27 (22.9\%) students correctly estimated their body weight and 13 students (11\%) overestimated their own weight and remaining 78 students (66.1\%) underestimated their body weight.

In our study, 84 students (56\%) perceived themselves as normal and, 44(29.3\%) and 22(14.7\%) students perceived their image as overweight and underweight respectively.

Among 150 students 36 (24\%) were willing to add some more weight and 60(40\%) students were willing to loose their present weight.

Table 4: Descriptive statistics

\begin{tabular}{|l|l|l|l|l|l|}
\hline & $\mathrm{N}$ & Minimum & Maximum & Mean & SD $^{*}$ \\
\hline Age (Yrs) & 150 & 18 & 25 & 20.35 & 1.171 \\
\hline Weight (Kg) & 150 & 40 & 110 & 67.77 & 13.45 \\
\hline Height (M) & 150 & 1.25 & 1.98 & 1.68 & 0.11 \\
\hline BMI & 150 & 15.60 & 44.16 & 24.25 & 4.28 \\
\hline
\end{tabular}

*Standard Deviation

Maximum age was 25 years while minimum age was 18 years with mean age $20.35 \pm 1.171$. Minimum and maximum weight was $40 \mathrm{~kg}$ and $110 \mathrm{~kg}$ respectively with mean weight $67.77 \pm 13.45$. In our study group, minimum and maximum height was $1.25 \mathrm{~m}$ and $1.98 \mathrm{~m}$ with mean height $1.68 \pm 0.11$ meter. Minimum BMI was 15.60 and maximum was 44.16 with mean BMI $24.25 \pm 4.28 \mathrm{~kg} / \mathrm{m}^{2}$.

Table 5: Association of BMI with body weight and image perception

\begin{tabular}{|c|c|c|c|c|c|c|}
\hline & & \multicolumn{3}{|l|}{ BMI } & \multirow[b]{2}{*}{$P$ value } & \multirow[b]{2}{*}{ Significance } \\
\hline & & Normal (\%) & $\begin{array}{l}\text { Overweight } \\
(\%)\end{array}$ & $\begin{array}{l}\text { Underweight } \\
(\%)\end{array}$ & & \\
\hline \multirow{2}{*}{$\begin{array}{l}\text { Know their } \\
\text { Body Weight }\end{array}$} & Yes (n-118) & $68(57.7)$ & $41(34.7)$ & $9(7.6)$ & \multirow{2}{*}{0.172} & \multirow{2}{*}{ No } \\
\hline & No (n-32) & $17(53.1)$ & $15(46.8)$ & $0(0)$ & & \\
\hline \multirow{3}{*}{$\begin{array}{l}\text { Weight } \\
\text { Perception }\end{array}$} & Correct (n-27) & $16(59.2)$ & $8(29.6)$ & $3(11.2)$ & \multirow{3}{*}{0.039} & \multirow{3}{*}{ Yes } \\
\hline & Overestimation (n-13) & $11(84.6)$ & $0(0)$ & $2(15.4)$ & & \\
\hline & Underestimation (n-78) & $41(52.6)$ & $33(42.3)$ & $4(5.1)$ & & \\
\hline \multirow{3}{*}{$\begin{array}{l}\text { Image } \\
\text { Perception }\end{array}$} & Normal (n-84) & $61(72.6)$ & $21(25)$ & $2(2.4)$ & \multirow{3}{*}{0.001} & \multirow{3}{*}{ Yes } \\
\hline & Overweight (n-44) & $11(25)$ & $33(75)$ & $0(0)$ & & \\
\hline & Underweight (n-22) & $13(59.1)$ & $2(9.1)$ & $7(31.8)$ & & \\
\hline \multirow{3}{*}{$\begin{array}{l}\text { Desired Body } \\
\text { weight }\end{array}$} & To add weight (n-36) & $24(66.7)$ & $3(8.3)$ & $9(25)$ & \multirow{3}{*}{0.001} & \multirow{3}{*}{ Yes } \\
\hline & To lose weight (n-60) & $20(33.3)$ & $40(66.7)$ & $0(0)$ & & \\
\hline & $\begin{array}{l}\text { To be with present weight (n- } \\
54 \text { ) }\end{array}$ & $41(75.9)$ & $13(24.1)$ & $0(0)$ & & \\
\hline
\end{tabular}

The prevalence of overweight/obese and underweight is high among those who did not know their body weight compared to those who knew their body weight. This relation was not found to be statistically significant.

Out of 150 study subjects, $118(78.7 \%)$ subjects knew their body weight and among those who knew their body weight, $78(66.1 \%)$ of study subjects underestimated their body weight and $13(11 \%)$ over estimated 
their body weight. The prevalence of overweight/obesity was high among those who underestimated their body weight $(42.3 \%)$. While none of the overweight subjects overestimated their body weight. The prevalence of underweight was high among the subjects who overestimated their body weight $(15.4 \%)$ compared to subjects who underestimated (5.1\%). This relationship was statistically significant.

Significant relationship was seen between image perception and BMI. Among the subjects who perceived themselves as of underweight, 2 (9.1\%) subjects were overweight/obese, and $13(59.1 \%)$ were of normal weight. Among the subjects who perceived themselves as of overweight/ obese, no-one was underweight and $21(25 \%)$ were of normal weight.

In this study, desired body weight and BMI was significantly associated. Those participants who want to loose their weight had significantly more BMI.

\section{Discussion}

The present study throws light upon perception of study subjects on their body weight and image. This study revealed that $37.3 \%$ subjects were overweight/ obese, $6.0 \%$ were underweight, and remaining $56.7 \%$ were of normal weight. Knowing one's body weight is an important factor which has an influence on their body weight. Here $21.3 \%$ of study subjects did not know their body weight. This implies implying that they were not at all concerned about their body weight. Prevalence of overweight/obesity and underweight among them was $46.8 \%$ and $28.1 \%$ respectively. The prevalence of overweight/obesity and underweight was found to be low (34.7\% and 7.6 respectively) among the subjects who knew their body weight. Not knowing one's body weight may act like a double-edged sword because if an individual does not know his/her body weight, it may lead to either of the two extremes of malnutrition.

In the present study, the subjects who knew their body weight were asked to write their body weight and then their written body weight was compared with their actual body weight. $77.1 \%$ subjects had false perception of their body weight i.e., $66.1 \%$ of subjects underestimated their body weight and $11 \%$ overestimated their body weight. The prevalence of overweight/obesity was high among those who underestimated their body weight $(42.3 \%)$ compared to subjects who overestimated $(0 \%)$, but the prevalence of underweight was high among the subjects who overestimated their body weight $(15.4 \%)$ compared to subjects who underestimated (5.1\%). Study on 'Body Image Perception and Attempts to Change Weight among Female Medical Students at Mangalore' by Priya et al. ${ }^{28}$ showed that 25(17\%) subjects were undernourished while $111(75.5 \%)$ and $11(7.5 \%)$ were normally nourished and overweight respectively. Out of 147 subjects, 35(23.8\%), $95(64.6 \%)$ and $17(11.6 \%)$ felt that they were lean, normal and overweight respectively. Regarding image satisfaction, 98(66.7\%) was satisfied with their image. Out of 49 who were not satisfied with their body image, 30 (20.4\%) wanted to reduce weight. Skipping meals was practiced by $42(28.6 \%)$ of subjects. ${ }^{15}$

The prevalence of faulty body images was observed among the respondents. Around $56 \%$ of the study subjects perceived themselves as of having normal weight. Only $72.6 \%$ of them were actually of normal weight and $25 \%$ of them were overweight and $2.4 \%$ were underweight. Among the subjects who perceived themselves as of underweight, $9.1 \%$ were overweight / obese and $59.1 \%$ were of normal weight. Earlier studies by Levy and Heaton ${ }^{16}$ and Story et al. ${ }^{17}$ have also reported the prevalence of faulty body images among college girls. Study conducted by Ash and McClelland ${ }^{18}$ have reported that a vast majority of subjects under their study listed a desirable weight loss. Lindberg and $\mathrm{O}^{\prime} \mathrm{Neil}^{19}$ have also reported that majority of the respondents in his study were bothered about being overweight. Sztainer and Hannan ${ }^{20}$ have also reported that half of the girls under their study were trying to lose weight.

\section{Conclusion And Recommendations}

This study found considerable differences in body weight and image perception and, prevalence of overweight/obesity. The study indicates that large proportion of the subjects could not appropriately classify their weight status. Body weight perception and dissatisfaction are major correlates for weight control practices. Overweight subjects should be better informed and empowered to follow recommended weight loss strategies. Gaps still exist within undergraduate medical education including specific training that addresses obesity and long-term studies showing that such training is retained.

\section{References}

[1]. World health Organization. Non communicable diseases in south East Asia region. New Delhi: Regional Office for South East Asia, India; 2002.

[2]. Reilly JJ, Dorosty AR. Epidemic of obesity in UK children. Lancet 1999;354:1874-5.

[3]. Keil U, Kuulasmaa K. WHO Monica project: Risk factors. Int J Epidemiol 1989;18(3 Suppl 1):S46-55.

[4]. K. Park. Park's textbook on preventive and social medicine. Jabalpur: Banarasidas Bhanot publishers;22 ${ }^{\text {nd }}$ Edition. 2005. p. 316.

[5]. Sharma B, Mahajan H, Suryawanshi SR. "Physical Exercise: An Effective Intervention In Increasing Self-Esteem of Obese Patients. Int J Med Health Sci. 2012;1(4):53-9.

[6]. Mahajan H, Padvi MV. Health profile of Diabetic patients in an urban slum of Mumbai, India. Innovative Journal Of Medical And Health Science, 2013;3(3). 
[7]. Mahajan H, Kazi Y, Sharma B, Velhal GD. Health Education: an Effective Intervention in Hypertensive Patients. International Journal of Recent Trend in Science and Technology 2012;4(2):77-82.

[8]. Gardner RM. Methodological issues in assessment of the perceptual component of body image disturbance. $\mathrm{Br} \mathrm{J}$ Psychol. 1996;87:327-37.

[9]. Strauss A, Corbin J. Basics of qualitative research: Techniques and procedures for developing grounded theory. 2nd ed. Thousand Oaks CA: Sage; 1998.

[10]. Stice E, Cameron RP, Killen JD, Hayward C, Taylor CB. Naturalistic weight-reduction efforts prospectively predict growth in relative weight and onset of obesity among female adolescents. J Consult Clin Psychol 1999;67:967-74.

[11]. Field AE, Austin SB, Taylor CB, Malspeis S, Rosner B, Rockett HR, et al. Relation between dieting and weight change among preadolescents and adolescents. Pediatrics 2003;112:900-6.

[12]. Cash TF, Pruzinsky T. Body image: Development, deviance, and change. New York: Guilford Press 1990. p. $20-4$.

[13]. Desmond SM, Price JH, Gray N, O'Connell JK. The etiology of adolescents' perceptions of their weight. J Youth Adolesc 1986;15:461-74.

[14]. Johnson-Taylor WL, Fisher RA, Hubbard VS, Starke-Reed P, Eggers PS. The change in weight perception of weight status among the overweight: Comparison of NHANES III (1988-1994) and 1999-2004 NHANES. Int J Behav Nutr Phys Act 2008;5:9.

[15]. D Priya, K S Prasanna, S Sucharitha, Nafisa C Vaz. Body Image Perception and Attempts to Change Weight among Female Medical Students at Mangalore. Indian J Community Med. 2010;35(2):316-20.

[16]. Levy AS, Heaton AW. Weight control practices of U.S. adults trying to lose weight. Ann Intern Med 1993;117:661-6.

[17]. Story M, Hanck FR, Broussand BA, White LL, Resnick MP, Bluns RW. Weight perceptions and weight control practices in American Indian and Alaska Native Adolescents. Arch Pediatric Adolescent Med 1994;148:567-71.

[18]. Ash SL, McClelland JW. Exploring attitudes towards body weight and eating behaviours of women in college. The Forum for Family and Consumer Issues 2001;6:1-3.

[19]. Lindberg KL, O'Neil CE. Knowledge, attitudes and practices about weight and weight control in a convenience sample of female dietetics students. J Am Dent Assoc 2001;101:A-17.

[20]. Neumark-Sztainer D, Story M, Hannan PJ, Perry CL, Irving LM. Weight-related concerns and behaviors among overweight and non-overweight adolescents: Implications for preventing weight-related disorders. Arch Pediatr Adolesc Med 2002;156:171-8. 